\title{
Impact of Islanding Detection Time Duration on the Stable Operation of a Synchronous Generator Controlled Microgrid
}

\author{
N. W. A. Lidula ${ }^{1}$ A. D. Rajapakse ${ }^{2}$ D. Muthumuni ${ }^{3}$ - C. Senkow ${ }^{4}$
}

Received: 7 September 2015 / Accepted: 10 December 2016 / Published online: 10 January 2017

(C) Springer Science+Business Media Singapore 2017

\begin{abstract}
This paper presents the impact of the time duration taken to change the control mode of a microgrid from grid connected operation to islanded operation (control mode transition delay) on the stability of a microgrid. A detailed microgrid simulation model was developed and its frequency and voltage control was designed based on the most generic schemes identified after a profound literature survey on practical microgrids. The simulation study results revealed that the control mode transition delay has a significant impact on the amount of load that need to be shed to preserve the stability of the islanded microgrid. The control mode transition delay also has an impact on the power quality.
\end{abstract}

Keywords Critical transition period - Distributed generation · Frequency and voltage control $\cdot$ Microgrid control

N. W. A. Lidula

lidula@elect.mrt.ac.lk

A. D. Rajapakse

athula@ee.umanitoba.ca

D. Muthumuni

dharshana@hvdc.ca

C. Senkow

csenkow@hydro.mb.ca

1 Department of Electrical Engineering, University of Moratuwa, Moratuwa, Sri Lanka

2 Department of Electrical \& Computer Engineering, University of Manitoba, Manitoba, Canada

3 Manitoba HVDC Research Center, Manitoba, Canada

4 Manitoba Hydro, Manitoba, Canada

\section{Introduction}

Microgrid is particularly a portion of an electric power system encompassing variety of generators, energy storages and customer loads. It can operate in parallel with the grid or as an autonomous power island.

Microgrids could be an attractive option to harness the benefits offered by Distributed Generators (DG), eliminating the constraints on high penetration of DGs. Substantial environmental benefits may be gained through the utilization of energy efficient generation technologies and renewable energy resources. Microgrids could reduce the network losses, defer the high investment costs required for network upgrades and also reduce the central generation reserve requirements. DGs provide local voltage support and microgrid as a whole increases the overall system reliability $[1,2]$.

An in-depth review of microgrid research around the world is presented in [3]. The IEEE STD 1547.4-2011 on Guide for Design, Operation, and Integration of Distributed Resource Island Systems with Electric Power Systems [4], addresses the issue of intentional islands, which was missing in IEEE STD 1547-2003 [5] for Interconnecting Distributed Resources with Electric Power Systems. Although there are numerous studies on voltage, frequency, and transient stability of microgrids during islanded and parallel operation, there is lack of literature on how the microgrid control mode transition from parallel to islanded operation is achieved, and its effect on the subsequent stability of the islanded microgrid. The control mode change-over time depends on the response time of the islanding detection technology used. In addition to changing of frequency and voltage control modes of generators, an islanded microgrid often requires under-frequency/under-voltage load shedding schemes to automatically drop loads to prevent the complete collapse of the microgrid. 
With respect to the parallel to islanding mode transition, IEEE STD 1547.4-2011 [4] states that "at the time of the microgrid separating from an area EPS and forming the island, transient and dynamic voltage effects can arise due to the redistribution of energy stored in the large inertia machines if exist in the island". In addition to the microgrid stability, power quality during the transition can also be an issue in specific situations. The voltage-sensitive loads such as semiconductor manufacturing, requires operation change-over times of less than $50 \mathrm{~ms}$ or otherwise the voltage should be maintained above $50 \%$ of the rating at any time of operation [2]. Thus, the capability of existing islanding detection technologies to detect the islanding event and change the mode of control of the microgrid in a timely manner needs to be examined. The islanding detection time depends on the technique used and the power imbalance in the island, or on the communication delays, if transfer trip arrangement is used.

According to [6], real power control of the critical generator of a medium voltage microgrid needs to be activated within 2 to 5 cycles to avoid potential angle instabilities. The microgrid considered in [6] has a 5 MVA synchronous generator and a 2.5 MVA VSC interconnected DC source, which is considered as the critical generator. The study further shows that waiting for $500 \mathrm{~ms}$ after islanding process to change the real power control of the VSC based generator leads to angle instability of the synchronous generator.

In [7] it discusses many elements of microgrid components, technologies and system configurations that can be used for "advanced microgrids" development. The paper focuses on microgrids up to $10 \mathrm{MW}$ capacity. It has indicated that inverters must be disconnected within $1 \mathrm{~s}$ when microgrid connection to the utility is lost. However, there is no further discussion given on that statement analyzing why $1 \mathrm{~s}$ time period is considered.

This paper particularly looks into the microgrid behavior in the transition period from grid connected to islanded operation and examines the effects of being fast or slow in the transition on the stability of the islanded microgrid. Although it is understood that fast transition would be desirable, proper studies during operating mode transfer could confirm the specific protection relay requirements for the stable operation of microgrids in islanded operation. In order to properly investigate the above, it is important to simulate a detailed model of a realistic microgrid. Therefore, a microgrid test system with generic frequency and voltage controls, and a load shedding scheme was developed. The effects of control mode transition delay on the microgrid were studied through simulations for a wide range of power imbalanlances in the microgrid. Sensitivity of the frequency and voltage responses to factors such as the inertia of the microgrid was also analyzed.

\section{Modeling the Microgrid Test System}

The microgrid test system was modeled based on the observations and conclusions made from the literature survey (by the same authors) on microgrid research [3]. The objective of this paper is to study the microgrid behavior during and immediately after the period of control mode transition from grid connected to islanded operation. Thus, the focus lies more in a medium voltage industrial microgrid having critical loads than a low voltage residential microgrid. Accordingly, the microgrid test system used in this study was derived from the CIGRE MV benchmark test system. The system was originally developed for DG interconnection studies, and was based on an actual power system [8]. For this study, it was augmented with the features necessary for microgrid operation [3, 4], which includes the voltage and frequency control of the generators, and a load shedding scheme. Although several sophisticated microgrid control systems designed to specific microgrid systems can be found in literature [3], the most generic frequency and voltage controls $[3,4]$ and the conventional static load shedding scheme were used in this study with the intention of obtaining more general conclusions. The controllers were developed in such a way that the test system meets the control and power quality requirements specified in IEEE STD 1547.4-2011 [4].

Figure 1 presents the modeled microgrid test system. It is an unbalanced system having a total base load of 6.39

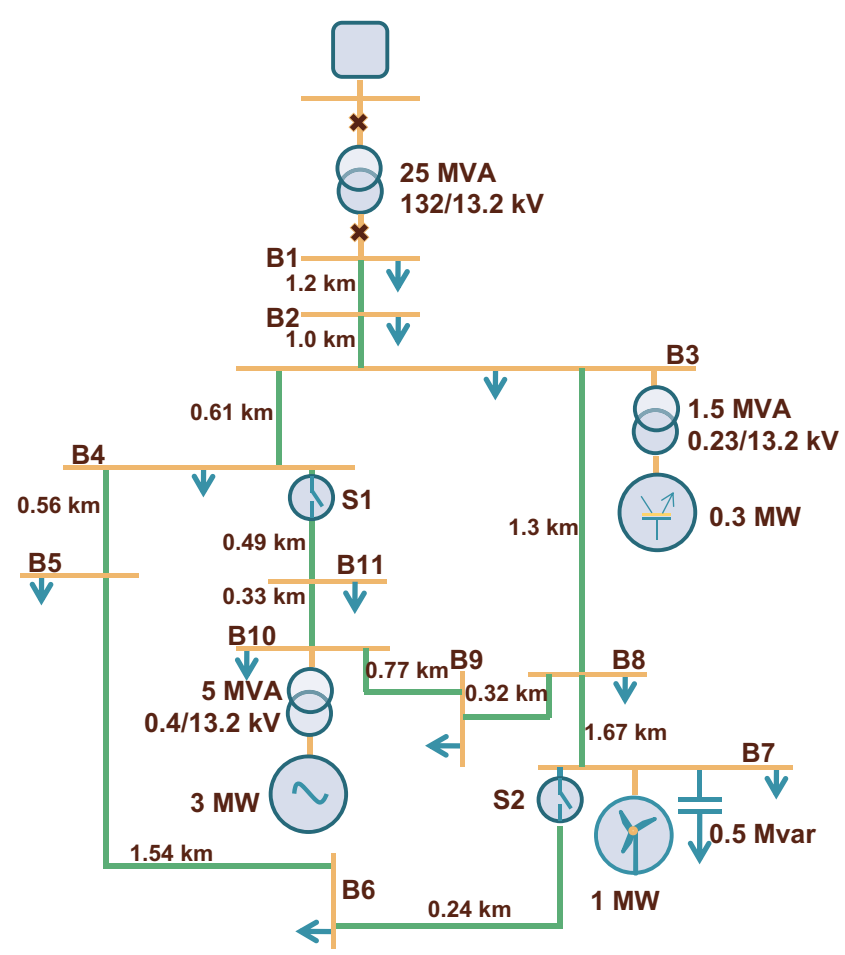

Fig. 1 Microgrid test system 
MW and 2.47 Mvar. To emulate a real microgrid, three different sources of DGs were connected considering both the recommendations made in [8] and the load flow solution of the system without DGs. When the DGs are not connected, bus-10 is one of the weakest buses and bus- 3 is one of the strongest buses in the system according to the voltage levels. Therefore, a $3 \mathrm{MW}$ steam turbine driven synchronous generator was connected to bus-10, and a 0.35 MVA DC source was connected to bus-3 via a Voltage Source Converter (VSC) representing a photovoltaic system. Also, a $1 \mathrm{MW}$ wind turbine driven fixed speed induction generator was connected to bus-7 with 0.5 MVars of capacitive compensation. A high capacity DG (the synchronous generator) was used in this study to avoid the necessity of an energy-storage.

All loads in the network were simulated as constant RL loads. The unbalanced load distribution among the 11 Buses of Fig. 1 is given in Appendix A. Part of the loads was used as controllable loads to shed at an event of islanding to control frequency and voltage. The system has two switches S1, S2 (which are kept normally open) making it possible to change the network configuration from radial to ring operation. Simulation studies were carried out using PSCAD/EMTDC power system simulation software.

\section{Microgrid Control Strategy}

The microgrid control strategy developed in this paper is summarized in Table 1, and explained in the following sub sections. Detailed description on modeling of this microgrid test system is given in [9] by the authors.

\section{Generator Controls}

As explained in "Modeling the Microgrid Test System", a steam turbine driven synchronous generator representing a co-generation plant was connected to Bus 10. Standard

Table 1 Microgrid control strategy

\begin{tabular}{lll}
\hline Unit & $\begin{array}{l}\text { Grid connected } \\
\text { operation and in } \\
\text { Transition }\end{array}$ & Islanded operation \\
\hline Synchronous generator & $\begin{array}{l}\text { Droop control with } \\
\text { constant power set } \\
\text { point }\end{array}$ & $\begin{array}{l}\text { Isochronous } \\
\text { Generator }\end{array}$ \\
Induction generator & $\begin{array}{l}\text { Constant PQ } \\
\text { Constant PV }\end{array}$ & $\begin{array}{l}\text { Constant PQ } \\
\text { Constant PV } \\
\text { VSC based generator }\end{array}$ \\
Nontrollable loads & Shed using a static \\
& & $\begin{array}{l}\text { load shedding } \\
\text { scheme }\end{array}$ \\
\hline
\end{tabular}

synchronous generator and steam turbine models available in PSCAD were used, and they were configured using typical values $[10,11]$. The control block diagram of the plant is shown in Fig. 2.

The standard IEEE alternator supplied rectifier excitation system (AC1A) was used for voltage control and a power system stabilizer (PSS) was also incorporated to improve the system damping. The block diagram of AC1A exciter with the PSS is given in Appendix B.1.

As shown in Fig. 2, the governor used for frequency control is operating in two modes, depending on whether the microgrid is islanded or not (grid connected). In the grid connected operation, synchronous generator is in droop control with constant power set point. Thus, typical values are used for the droop, $\boldsymbol{R}$ and time constants [7]. In the islanded mode, synchronous generator is run as an isochronous generator allowing it to respond for any load change. With the requirement to bring the frequency back to nominal frequency, the steam turbine valves are actuated relative to the amplified speed error. Thus, in order for the governor to operate as an isochronous governor, the droop setting is made nearly equal to zero. This in turn effectively changes the governor to constant frequency operation. The block diagram of the electro-hydraulic controlled governor with its corresponding parameters is given in Appendix B.2.

The modeled wind turbine connected to Bus 7 , drives a fixed speed induction generator, and it is integrated with a pitch control mechanism to maintain a constant power output in both parallel and islanded operation of the microgrid. A 0.5 Mvar capacitor bank is connected at the generator terminal for reactive power compensation. The initial pitch angle is found as given in [12] by calculating the power coefficient to give $0.6 \mathrm{MW}$ power output at a constant wind speed of $12 \mathrm{~ms}^{-1}$. The block diagram of the wind turbine governor in pitch control is given in Appendix B.3.

A photovoltaic system was represented through a DC current source connected via a VSC. Considering the unbalanced nature of the microgrid, the VSC based system is connected to one of the strongest buses, Bus 3. The VSC was modeled to operate as a constant PV generator under both grid-connected and islanded operation of the microgrid. Since the system is unbalance, simple decoupled control of VSC was not possible [13, 14]. Therefore, PI controller was designed for controlling the output power, and depending on the DC voltage error, phase angle of the Sine-wave Pulse Width Modulator (SPWM) was adjusted. Similarly, a PI controller was designed to control the terminal output voltage after the transformer. The terminal voltage error was minimized by adjusting the modulation index of the SPWM. The initial parameters of the PI controllers were found by trials and later optimized using simplex method in the optimization tools available in PSCAD/EMTDC [15]. The schematic diagram of the developed VSC system and 
Fig. 2 Block diagram of the synchronous generator with frequency and voltage control

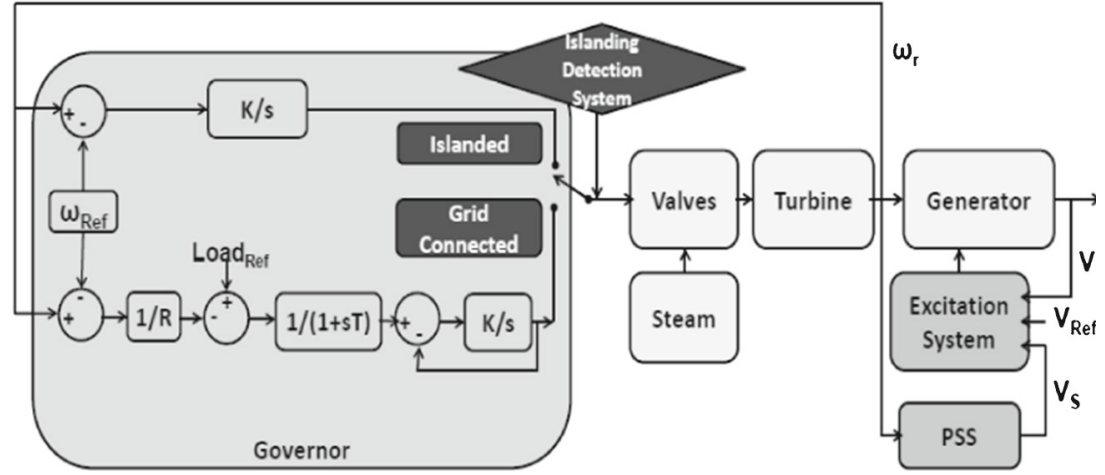

the SPWM firing angle control via direct control of terminal voltage and DC voltage is given in Appendix B.4.

\section{Load Shedding}

To prevent the complete collapse of the microgrid when operating as an island, under-frequency load shedding schemes are used to automatically drop loads in accordance with a predetermined schedule to balance the load and available generation. Such action must be fast and sufficient magnitude of controllable loads should be shed to conserve sensitive and essential loads and recover from the under frequency condition. Although many different load shedding algorithms can be found in literature, static and dynamic under-frequency load shedding are the two concepts widely applied $[16,17]$.

In a static load shedding scheme, it opens predefined circuit breakers when a given under frequency level is reached. In the advanced schemes, both frequency and rate of change of frequency is fed in to the controller and when the frequency goes below a preset value and if the rate of change of frequency is more than its pre-set value, the controller initiate a signal to trip the loads assigned priority 1 (stage 1 ). If the frequency goes further down, the next stage of loads will be released and this will continue until the frequency stabilizes to its normal value. Priorities are assigned to the feeders in the design stage, considering their relative importance as well as the normal loading of each feeder. However, in static load shedding, the real load behind the breaker or how much load has to be shed in order to reestablish the load balance is generally unknown $[16,17]$.

In dynamic load shedding, the amount of load to be shed at each stage is determined by considering the magnitude of generation loss and available load on each feeder, in addition to the frequency characteristic of the system. This allows for the shedding of larger load for larger system imbalance, and smaller load for smaller system imbalance. There are different approaches for dynamic load shedding [17].
Static load shedding schemes are more common in practical power systems due to its simplicity $[18,19]$. Therefore, this paper uses a static load shedding scheme to study the system behavior in the control mode transition period of the microgrid. It involves 4 steps to design a static load shedding scheme: 1) calculation of total load to be shed, 2) deciding the number of load shedding stages, 3 ) determining the size of load to shed at each stage and 4) setting the frequency thresholds and time delays [16]. The load shedding scheme that is developed based on [19] is shown in Fig. 3.

If frequency dependency of loads is neglected, the total overload can be calculated using Eq. 1 .

$\%$ Overload $=\frac{\text { Load }- \text { Remaining Generation }}{\text { Remaining Generation }} \times 100$

Equation 1 implies that $100 \%$ overload corresponds to a $50 \%$ loss of generation. The total load of the microgrid in Fig. 1 is $6.39 \mathrm{MW}$ (at 1 pu voltage) resulting in a requirement of shedding $3.195 \mathrm{MW}$ of loads at a $100 \%$ overload on the synchronous generator.

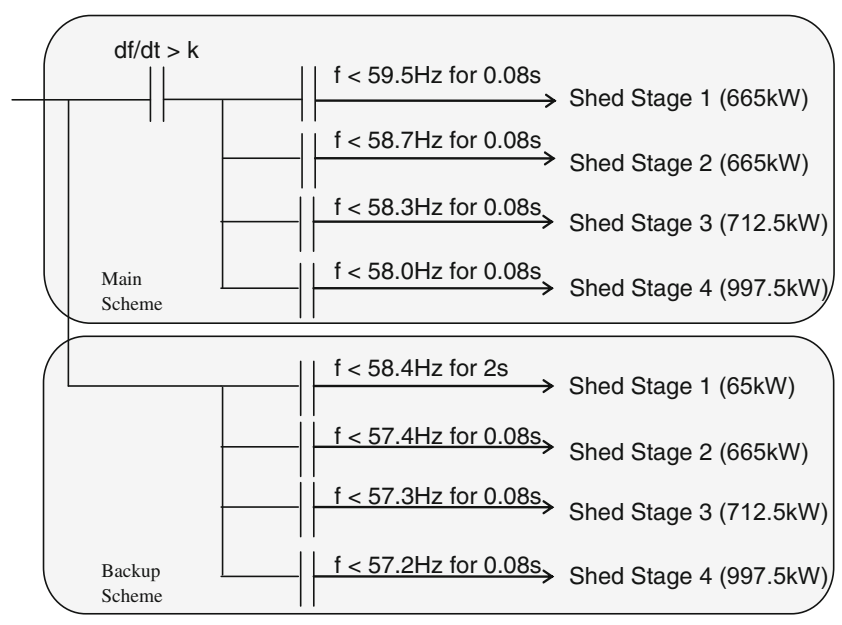

Fig. 3 Schematic representation of the designed load shedding scheme 
Generally four load shedding steps are recommended considering the economics aspects and complexity. The value of the load to be shed at various stages usually increases with every stage [17]. Having the loads being modeled as constant RL loads, the effective total load would be less than the theoretical value calculated at 1 pu voltage. Thus, considering the available feeder loads, it is selected to shed $10.5 \%, 10.5 \%, 11.5 \%$ and $15 \%$ of the total load in the four stages.

The frequency at which the load shedding program starts was decided by considering the lowest frequency at which generators are allowed to run for long periods. According to the IEEE Standard 1547-2003 [5], generators connected to a distribution grid are required to tolerate $\pm 1 \%$ frequency variation in the steady state. Thus, $59.5 \mathrm{~Hz}$ was selected as the load shedding initiating frequency.

The lowest setting should be above the critical frequencies of the generators, and the IEEE Standard 1547-2003 [5] recommends disconnecting distributed generators if the frequency drops below $57 \mathrm{~Hz}$ for a period longer than 0.16 $\mathrm{s}$. This frequency threshold coincides with the under frequency setting of steam turbine generators, which is around $57 \mathrm{~Hz}$ [16]. Considering the aforementioned critical minimum frequency setting as well as the fact of unavailable spinning reserve in the microgrid, the minimum frequency of the load shedding scheme was selected as $58 \mathrm{~Hz}$ to avoid critical conditions. The intermediate frequency settings depend on the number of stages used in the system. In general, the setting frequency of the various stages is divided into equal frequency steps for nearly linear frequency decay. However, to avoid the shedding of more loads than necessary to stabilize the frequency in this particular microgrid test system, the frequency step between stage 1 $(59.5 \mathrm{~Hz})$ and stage $2(58.7 \mathrm{~Hz})$ were purposely kept higher.

It is advantageous to keep the time delay setting of the frequency relays as short as possible. This avoids an unnecessarily large decay of frequency, avoiding spurious tripping of loads. Time delays of the relays are set at 5 cycles.

The requirement of a load shedding is determined by the rate of change of frequency of the system. The critical rate of change of frequency setting is thus, determined by considering the system's ability to stabilize the frequency at an islanding happened in a balanced situation. The critical rate of change of frequency settings of 1.71, 1.2 and $0.98 \mathrm{~Hz} / \mathrm{s}$ are selected at the inertia constants of $1 \mathrm{~s}, 2 \mathrm{~s}$ and $3 \mathrm{~s}$ of the synchronous generator respectively.

To avoid system collapse, time delayed back up relays are provided at each stage of the load shedding scheme, which operates regardless of the initial rate of change of frequency. Figure 3 presents the relay settings, which were found by initial simulation studies. This load shedding scheme is developed with the intention to stabilize the system by shedding minimum amount of loads as possible.

\section{Simulation Results and Analysis}

It was considered that the operating points of synchronous generator, VSC based source and the wind farm are at 0.9 $\mathrm{pu}, 1 \mathrm{pu}$ and $0.6 \mathrm{pu}$ respectively at the time islanding happens for all the simulations carried out in this paper. The inertia constant of the wind farm was kept constant at $0.5 \mathrm{~s}$ and synchronous generator inertia was changed $(1 \mathrm{~s}, 2 \mathrm{~s}$ and $3 \mathrm{~s})$ to study the responses under varying inertia constants of the microgrid $(0.8 \mathrm{~s}, 1.5 \mathrm{~s}$ and $2.2 \mathrm{~s})$. Different power imbalances in the microgrid were simulated by disconnecting some loads.

The paper defines the active power imbalance $(\boldsymbol{\Delta} \boldsymbol{P})$ as given by Eq. 2, which means the grid power being lost as a percentage of the total power consumption. The "+" sign indicates the microgrid was importing real power from the grid at the time of islanding and the "-" sign indicates microgrid was exporting power to the grid at the time of islanding.

$$
\Delta P=\frac{ \pm P_{\text {Grid }}}{P_{\text {Grid }}+P_{\text {SynGen }}+P_{V S C}+P_{\text {Wind }}} \times 100
$$

\section{Microgrid Behavior at Islanding}

System frequency, rate of change of frequency and terminal voltages are the basic $\mathrm{p}$ that characterize the system behavior upon a disturbance. Passive islanding detection methods use these parameters to identify a power island. In [20], response times of different passive islanding detection relays are compared. Table 2 presents average detection times of different passive islanding detection relays for the 250 islanding events tested in [20] for the same power system shown in Fig. 1.

Results reveal that over/under voltage relays take more than $600 \mathrm{~ms}$ while over/under frequency relays taking nearly $1 \mathrm{~s}$ to detect power islanding. It is concluded in [20] that both these relays present a larger non-detection zones as well.

Table 2 Comparison of response times of islanding detection methods [20]

\begin{tabular}{llll}
\hline Relay & \multicolumn{3}{l}{ Detection time (ms) } \\
\cline { 2 - 4 } & Synchronous & Wind & VSC \\
\hline Over/Under voltage & 649 & 650 & 628 \\
Over/Under frequency & 964 & 964 & 963 \\
Voltage vector Shift $3^{0} /$ cycle & 11 & 10 & 11 \\
Voltage vector Shift 10\% $/$ cycle & 15 & 13 & 13 \\
Voltage vector Shift 15\%cycle & 28 & 23 & 23 \\
Rate of change of frequency $0.1 \mathrm{~Hz} / \mathrm{s}$ & 164 & 163 & 162 \\
Rate of change of frequency $0.5 \mathrm{~Hz} / \mathrm{s}$ & 323 & 322 & 321 \\
Rate of change of frequency $1.2 \mathrm{~Hz} / \mathrm{s}$ & 456 & 456 & 455 \\
\hline
\end{tabular}




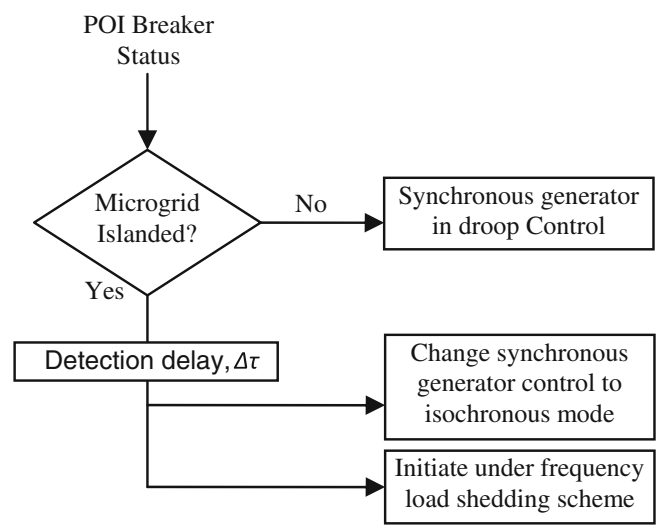

Fig. 4 Microgrid control changes involved upon disconnecting from the grid

From Table 2 it shows that voltage vector shift relay takes less than $30 \mathrm{~ms}$ to detect power islanding. However, in [20] it has shown that voltage vector shift relays' reliability is less at lower settings and presents a higher non-detection zone at higher relay settings. Rate of change of frequency relay response times, which indicates to be above $150 \mathrm{~ms}$, highly depends on the relay setting and power imbalance. In [20], it has shown that rate of change of frequency relay too has a considerable non-detection zone at higher settings while presenting low security at lower relay settings.

Study in [21] reveals similar results under an experimental study using commercial relays. Reference [22], which reviews islanding detection methods, declare that active methods take longer time than passive methods to detect islanding. Telecommunication based methods such as transfer trip schemes would be much faster but costlier to implement. The detection time depends on the communication method, and in general it is in-between $30 \mathrm{~ms}$ and 200 ms [23, 24]. A new methodology based on transient signals that uses discrete wavelet transform and pattern recognition techniques has shown a detection time less than two cycles, while being highly reliable in detecting islands [20,25].

\section{Impact of the Microgrid Control Mode Transition Delay on Power System Stability}

When the microgrid is islanded, the synchronous generator control mode is changed from droop control to isochronous operation. Therefore, even during the transition period, synchronous generator is in droop control. At the time of islanding microgrid loose the power exchange with the grid, $\boldsymbol{P}_{\text {grid }}$, causing power imbalance of $\boldsymbol{\Delta} \boldsymbol{P}$, which can be calculated using Eq. 2. Therefore, in order to establish the stability of the islanded microgrid, it requires to initiate the under frequency load shedding as discussed in "Microgrid Control Strategy" (B). Figure 4 presents the flowchart indicating the required control changes in a microgrid upon disconnecting from the main grid causing a $\boldsymbol{\Delta P}$ power imbalance.

In order to study the system behavior under different control mode transition delays $(\Delta \tau)$, the control mode of the synchronous generator is changed after a predetermined time interval $(\Delta \tau=0 \mathrm{~s}, 0.05 \mathrm{~s}, 0.1 \mathrm{~s}, 0.2 \mathrm{~s}, \ldots, 2 \mathrm{~s})$ from the time of microgrid islanding. The control mode transition
Fig. 5 Load shedding under different control mode transition delays $(\Delta \tau)$ at power imbalance of (a) $\Delta P=-3 \%$, (b)

$\Delta P=+1 \%$ and $(\mathbf{c})$

$\Delta P=+30 \%$ (a)

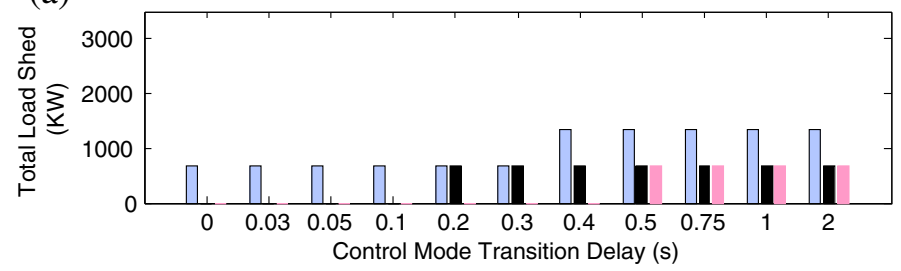

Power Imbalance $=-3 \%$

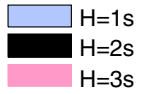

(b)

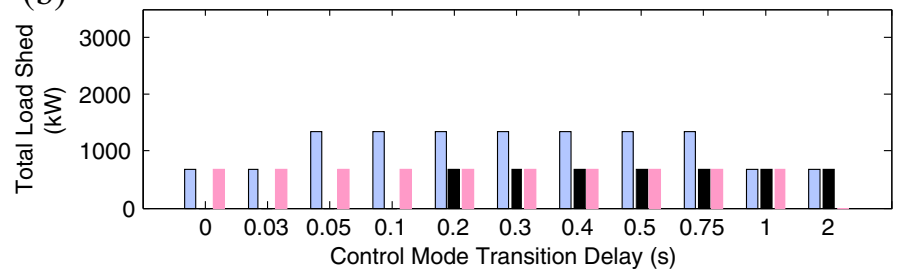

Power Imbalance $=+1 \%$

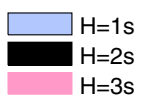

(c)

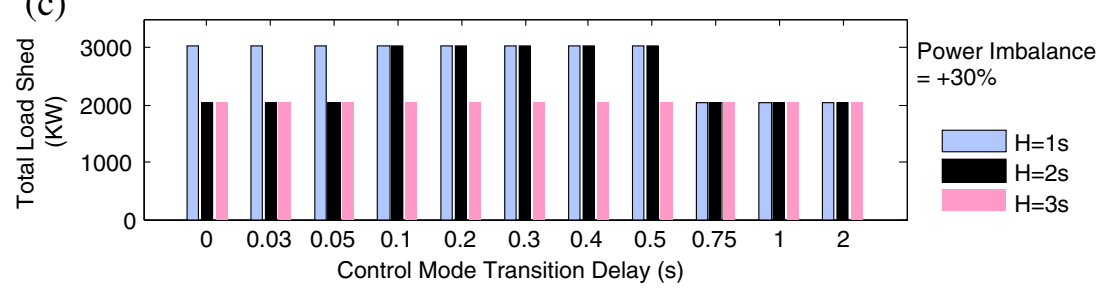


Fig. 6 Frequency variation under different $\Delta \tau$ for an islanding resulting $+1 \%$ power imbalance with synchronous generator's (a) $\mathrm{H}=1 \mathrm{~s}$, (b) $\mathrm{H}=2 \mathrm{~s}$, (c) $\mathrm{H}=3 \mathrm{~s}$
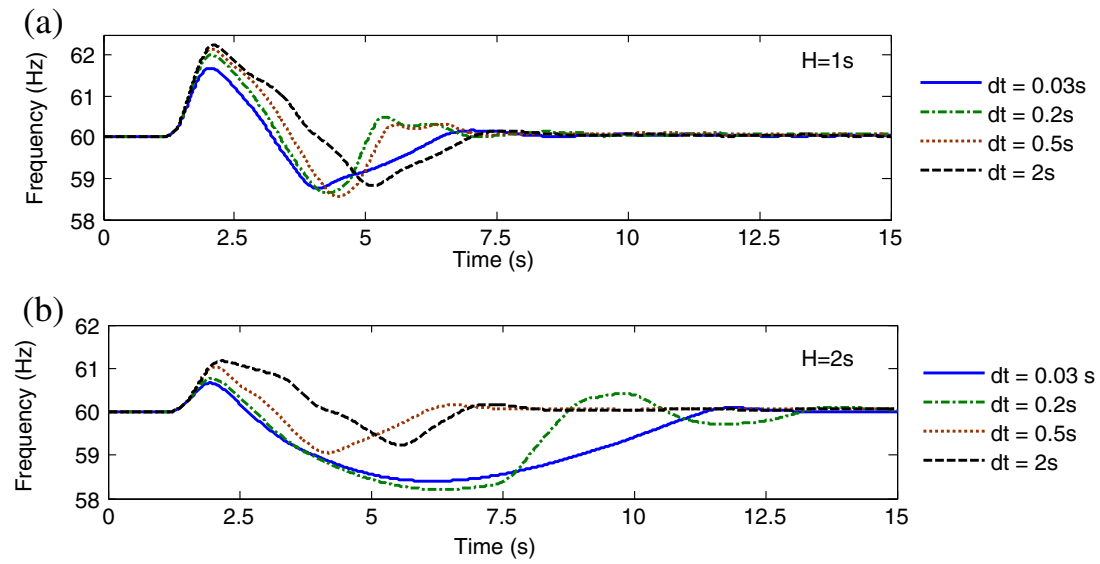

(c)

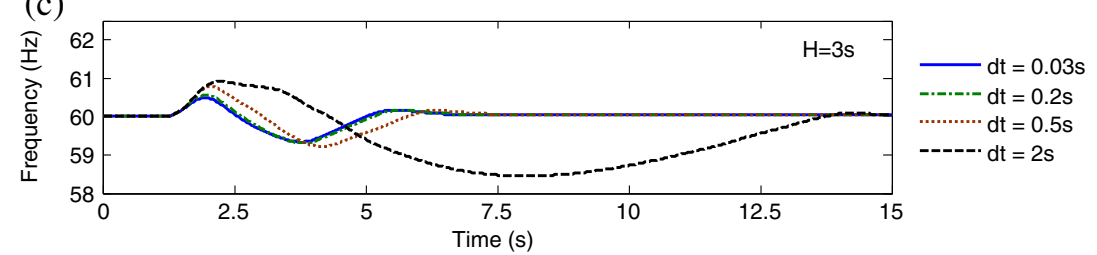

delay, $\Delta \tau$, basically comprised of the islanding detection time.

Figure 5 depicts the amount of load shed under different power imbalances $(\boldsymbol{\Delta P})$ for changing control mode transition delays $(\Delta \tau)$. The results are shown for three different inertia constants $(\mathrm{H}=1 \mathrm{~s}, 2 \mathrm{~s}$ and $3 \mathrm{~s})$ of the synchronous generator. To further illustrate the system behavior in transition period, system frequency variations under selected different transition delays $(\Delta \tau=0.05,0.2,0.5$ and $2 \mathrm{~s}$ ) for an islanding happening at $\mathrm{t}=1 \mathrm{~s}$ resulting $+1 \%$ power imbalance $(\boldsymbol{\Delta P}=+1 \%)$ are illustrated in Fig. 6. Similar results were observed with other power imbalances.
Fig. 7 Voltage variation in Phase $b$ of Bus 10 at an islanding with $\Delta P=+1 \%$ for synch. generator's $\mathrm{H}=$ (a) $1 \mathrm{~s}$, (b) $2 \mathrm{~s}$, (c) $3 \mathrm{~s}$

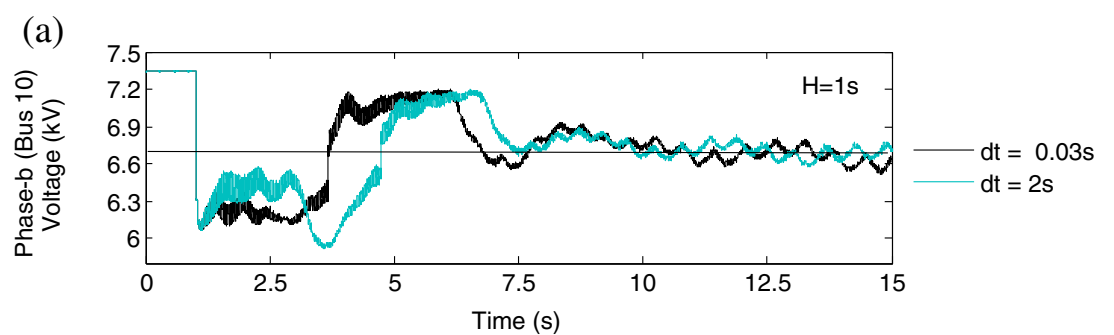

(b)

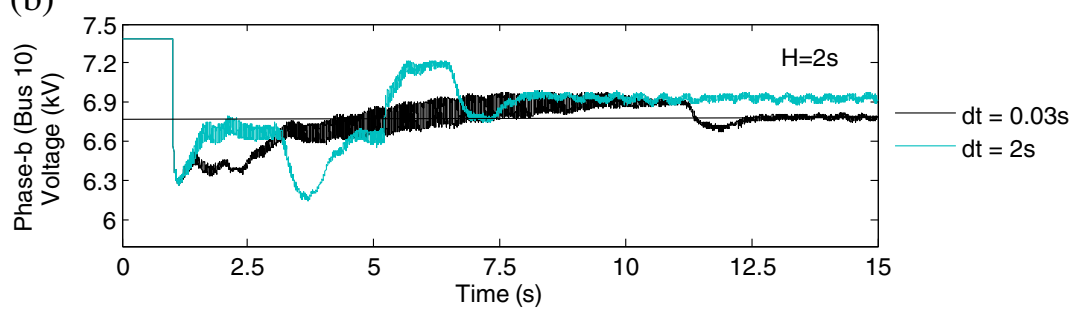

(c)

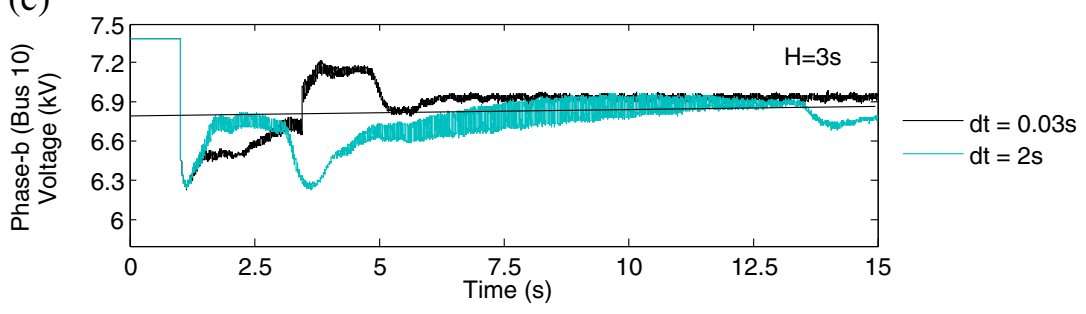




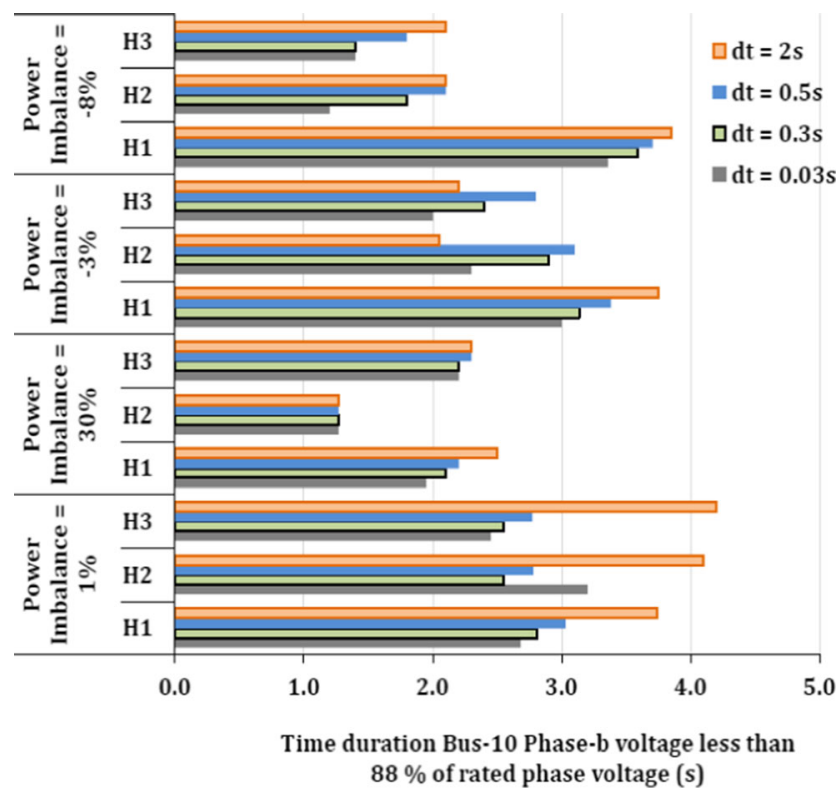

Fig. 8 Time duration the Phase-b of Bus-10 voltage being less than $88 \%$ with synchronous generator inertia, $\mathrm{H}=1 \mathrm{~s}, \mathrm{H}=2 \mathrm{~s}$ and $\mathrm{H}=3 \mathrm{~s}$

Figure 5a corresponds to a $-3 \%$ power imbalance. It indicates that for $\mathrm{H}=2 \mathrm{~s}$ and $\mathrm{H}=3 \mathrm{~s}$, if the control mode is changed without any delay (i.e. $\Delta \tau=0 \mathrm{~s}$ ), system frequency and voltage can be stabilized without shedding any load. However, in the case of $\mathrm{H}=2 \mathrm{~s}$, it starts shedding the stage-1 load if control mode transition is delayed by more than $0.2 \mathrm{~s}(\Delta \tau \geq 0.2 \mathrm{~s})$. In the case of $\mathrm{H}=3 \mathrm{~s}$, if transition is delayed by more than $0.5 \mathrm{~s}(\Delta \tau \geq 0.5 \mathrm{~s})$ it starts shedding stage- 1 load. In the case of $\mathrm{H}=1 \mathrm{~s}$, then it is required to shed only one stage of loads to stabilize the system frequency and voltage if the control mode is changed without any delay (i.e. $\Delta \tau=0 \mathrm{~s}$ ), but if $\Delta \tau \geq 0.4 \mathrm{~s}$, two stages of loads are shed.

Figure $5 \mathrm{~b}$ corresponds to $\mathrm{a}+1 \%$ power imbalance. In this case, it is required to shed only one stage of loads for $\mathrm{H}$ $=1 \mathrm{~s}$ and $3 \mathrm{~s}$, while it is not required to shed any load for $\mathrm{H}=2 \mathrm{~s}$, if the control mode is changed without any delay $(\Delta \tau=0 \mathrm{~s})$.

However, it shows that if $0.05 \mathrm{~s} \leq \Delta \tau<1 \mathrm{~s}$ with $\mathrm{H}=1 \mathrm{~s}$, then two stages of loads are shed. With $\mathrm{H}=2 \mathrm{~s}$, if $\Delta \tau \geq 0.2$ $\mathrm{s}$, one stage of loads is shed, introducing frequency swings in the microgrid.
When $\mathrm{H}=3 \mathrm{~s}$, only one stage of loads is shed as long as $\Delta \tau<2 \mathrm{~s}$, but there is no load shed when $\Delta \tau=2 \mathrm{~s}$. The frequency variations corresponding to these events are illustrated in Fig. 6.

Frequency swings are introduced in the system due to shedding of more loads than what is required to stabilize the frequency and voltage of the system. With $\mathrm{H}=2 \mathrm{~s}$ of the synchronous generator, when $\Delta \tau=0.2 \mathrm{~s}$, load was shed through the back-up load shedding step, which can be clearly observed from Fig. 6.

Figure $5 \mathrm{c}$ corresponds to the load shedding at a power imbalance of $=+30 \%$. If the control mode is changed without any delay $(\Delta \tau=0 \mathrm{~s})$, it is required to shed all four stages of loads with $\mathrm{H}=1 \mathrm{~s}$ and only three stages of loads required to be shed with $\mathrm{H}=2 \mathrm{~s}$ or $3 \mathrm{~s}$. However, it sheds only three stages when $\Delta \tau \geq 0.75 \mathrm{~s}$ with $\mathrm{H}=1 \mathrm{~s}$ and sheds all four stages when $0.1 \mathrm{~s} \leq \Delta \tau<0.75 \mathrm{~s}$ with $\mathrm{H}=2 \mathrm{~s}$.

Results show that the impact of control mode transition delay on frequency and voltage fluctuations of the microgrid is more significant and sensitive at low power imbalances $(\Delta \boldsymbol{P})$ and at low inertia constants $(\boldsymbol{H})$.

Figures $5 \mathrm{~b}$ and $\mathrm{c}$ showed that the amount of load shed for stabilizing frequency sometimes reduces back suddenly at longer control mode transition delays $(\Delta \tau>0.75 \mathrm{~s})$. The reason is the sustained voltage depression the system experience with longer control mode transition delays $(\Delta \tau)$. With the voltage depression, the relative power consumption of RL loads in the microgrid reduces, which results in lower rate of change of frequency in the system.

Figure 7 presents the voltage observed at the phase-b of the synchronous generator terminal (Bus 10) for two different control mode transition delays $(\Delta \tau=0.03 \mathrm{~s}$ and 2 $\mathrm{s})$. It shows the voltage response at $+1 \%$ power imbalance at islanding with synchronous generator inertia constants, $\mathrm{H}$ $=1 \mathrm{~s}, 2 \mathrm{~s}$ and $3 \mathrm{~s}$. The horizontal line in each graph of Fig. 6 corresponds to the $88 \%$ of rated voltage. According to IEEE Std. 1547-2003 [5], if the generator terminal voltages are in-between $50 \%$ and $88 \%$ of the rated voltage, the generator must be disconnected within $2 \mathrm{~s}$. However, it can be observed from Fig. 7 that with the increasing control mode transition delay (e.g. $\Delta \tau=2 \mathrm{~s}$ ), there is a high tendency for voltage to be depressed for a longer duration.

This is further illustrated by Fig. 8, which shows the time duration the Phase-b of Bus-10 voltage being less than $88 \%$
Table 3 Critical control mode transition delay $\left(\Delta \tau_{\text {critical }}\right)$

\begin{tabular}{llll}
\hline Inertia constant of synch gen, $\boldsymbol{H}(\mathrm{s})$ & \multicolumn{2}{l}{ Critical control mode transition delay $\left(\Delta \tau_{\text {critical }}\right)(\mathrm{s})$} \\
\cline { 2 - 4 } & $\begin{array}{l}-3 \% \text { power } \\
\text { imbalance }\end{array}$ & $\begin{array}{l}+1 \% \text { power } \\
\text { imbalance }\end{array}$ & $\begin{array}{l}+30 \% \text { power } \\
\text { imbalance }\end{array}$ \\
\hline 1 & 0.40 & 0.05 & 0.75 \\
2 & 0.20 & 0.20 & 0.10 \\
3 & 0.50 & 2.00 & $>2.00$ \\
\hline
\end{tabular}


for different microgrid inertia values, $\mathrm{H}$. It clearly shows the importance of having shorter control mode transition delay to overcome the long duration voltage depression.

\section{Critical Control Mode Transition Delay}

The simulation results indicate that there is a "critical control mode transition delay" $\left(\Delta \tau_{\text {critical }}\right)$. This can be defined as the control mode transition delay on and beyond which the resulting microgrid frequency and voltage responses significantly deviate from that resulting with control mode transition without any delay $(\Delta \tau=0 \mathrm{~s}) . \Delta \tau_{\text {critical }}$ for each test case is shown in Table 3.

The results obtained for this $6 \mathrm{MW}$ microgrid lead to a conclusion that, having a control mode transition delay less than $50 \mathrm{~ms}$ gives the same behavior as if the controllers are changed without any delay.

Taking more than $50 \mathrm{~ms}$ for changing the control mode could lead to undesirable behavior such as shedding of too many loads, long duration voltage depressions and generator tripping through under voltage relay. The system was more robust during control mode transition with higher inertia constants $(\mathrm{H}>2 \mathrm{~s}$ for this $6 \mathrm{MW}$ microgrid system). Under such high microgrid inertia, the critical transition time period shifted towards $400 \mathrm{~ms}$, which is otherwise 50 $\mathrm{ms}$ with lower inertias. These findings support the reported work on requirement of operating mode transition delay for angle stability in [6], despite the use of two contrasting control algorithms and different microgrid test systems.

\section{Conclusions}

The paper presented an analysis on the behavior of a microgrid during the control mode transition period. It revealed that if the control mode is changed within a certain time period, the microgrid attains the same frequency and voltage responses as that of a changeover without a delay. In low inertia microgrids, delaying the control mode transition period above a critical time period could lead to shedding more loads than what is required to stabilize the system frequency. At higher embedded inertia, a microgrid becomes more robust, and tolerates a longer transition delay.

The above conclusions point to the benefits of having a fast and reliable islanding detection device to activate control mode transition. Considering both, reliability and response time, transfer trip schemes or use of fast islanding detection methods such as the transients based islanding detection method proposed in [25] would be more suited for microgrids with reliability objectives. The conclusions are drawn for a substation level microgrid with a synchronous generator and no energy storage. Beside these findings, the microgrid test system developed in this paper could be effectively used in further studies on transient simulation of microgrids.

\section{Appendix A: Test System Loads}

\begin{tabular}{lllll}
\hline Bus & \multicolumn{3}{l}{ Phase load (kVA) } & Power factor \\
\cline { 2 - 3 } & A & B & C & \\
\hline B1 & 250 & 100 & 300 & 0.90 \\
B2 & 300 & 250 & 200 & 0.95 \\
B3 & 83.33 & 500 & 83.33 & 0.90 \\
B4 & 200 & 100 & 100 & 0.90 \\
B5 & 250 & 400 & 50 & 0.95 \\
B6 & 50 & 500 & 100 & 0.95 \\
B7 & 200 & 400 & 100 & 0.95 \\
B8 & 100 & 150 & 200 & 0.90 \\
B9 & 100 & 150 & 100 & 0.95 \\
B10 & 50 & 400 & 50 & 0.90 \\
B11 & 200 & 750 & 100 & 0.95 \\
\hline
\end{tabular}

Appendix B.1: Block diagram of AC1A exciter with the PSS [10]

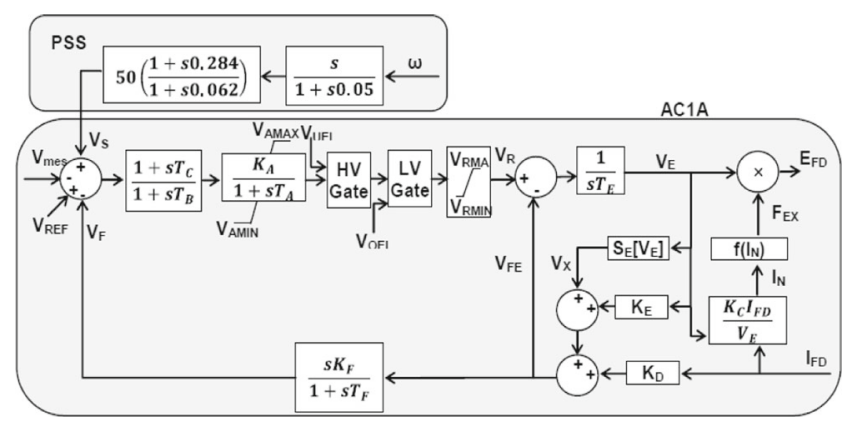

Appendix B.2: Block diagram of an electro-hydraulic controlled governor and its parameters in grid connected and islanded mode [10]

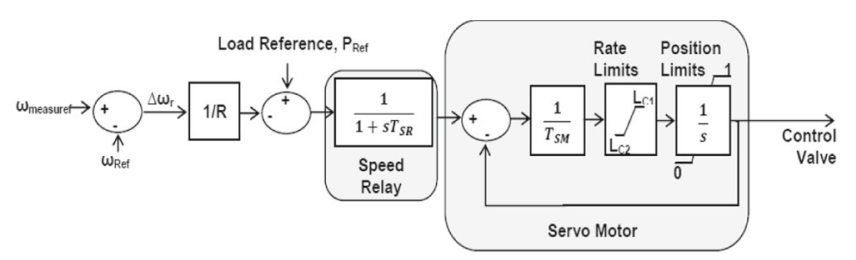

\begin{tabular}{|l|l|l|}
\hline Parameter & Grid connected operation (Droop) & Islanded Operation (Isochronous) \\
\hline Droop, $R$ & $0.05 \mathrm{pu}$ & $0.003 \mathrm{pu}$ \\
\hline Speed relay time const., $\mathrm{T}_{\mathrm{SM}}$ & $0.1 \mathrm{~s}$ & $0.1 \mathrm{~s}$ \\
\hline Opening Rate: $\mathrm{L}_{\mathrm{Cl}}, \mathrm{L}_{\mathrm{C} 2}$ & $1,-3$ & $1,-3$ \\
\hline Servo Position; $\mathrm{P}_{\text {_max }}, \mathrm{P}_{-}$min & 1,0 & 1,0 \\
\hline
\end{tabular}




\section{Appendix B.3: Block diagram of the wind turbine governor in pitch control [12]}

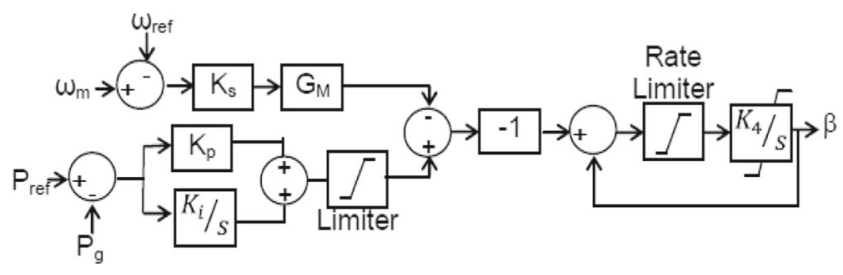

\section{Appendix B.4: The schematic diagram of the developed VSC system and the SPWM firing angle control via direct control of terminal voltage and DC voltage}

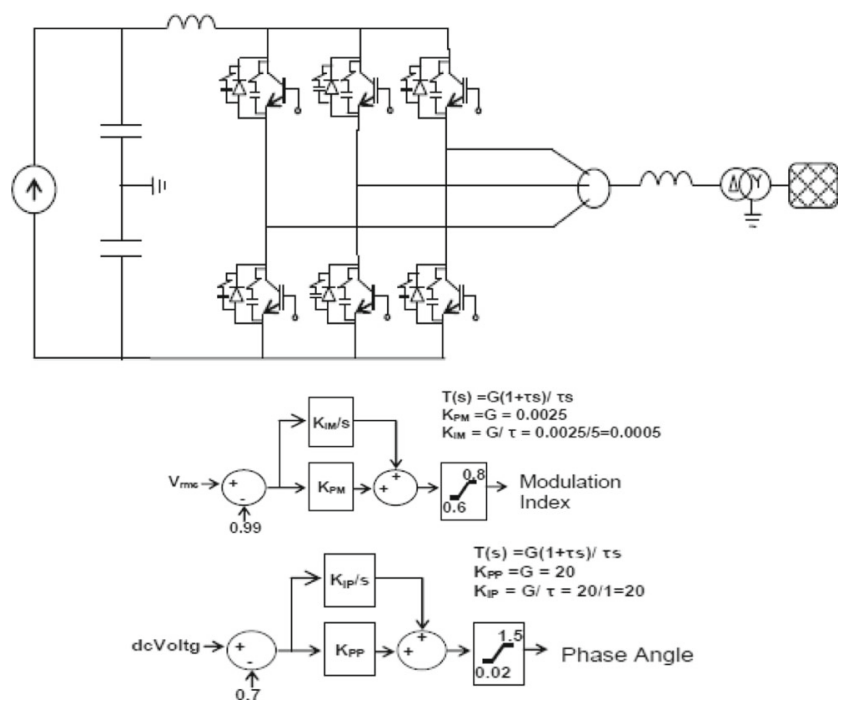

\section{References}

1. Jenkins N, Allan R, Crossley P, Kirschen D, Strbac G (2000) Embedded generation. IEE, UK

2. Chowdhury S, Chowdhury SP, Crossley P (2009) Microgrids and active distribution networks, IET Renewable Energy Series 6. IET, UK

3. Lidula NWA, Rajapakse AD (2011) Microgrids research: A review of experimental microgrids and test systems. Renew Sustain Energy Rev J 15:186-202

4. Guide for Design, Operation, and Integration of Distributed Resource Island Systems with Electric Power Systems, IEEE STD 1547.4-2011

5. (2003). Interconnecting Distributed Resources with Electric Power Systems, IEEE Standard 1547-2003

6. Katiraei F, Iravani MR, Lehn PW (2005) Micro-grid autonomous operation during and subsequent to islanding process. IEEE Trans Power Del 20(1):248-257

7. Sandia National Laboratories, The Advanced microgrid: integration and interoperability, SAND2014-1535, 2014 [online]. Available at: http://energy.gov/sites/prod/files/2014/12/f19/Advanced Microgrid_Integ ration-Interoperability_March2014.pdf
8. (2006). CIGRE C6.04.02 Task Force, Benchmark modeling and simulation for analysis, design, and validation of distributed energy systems

9. Lidula NWA, Rajapakse AD (2013) Behavior of a Microgrid during the transition from grid connected to islanded mode. In: Proceedings of International Conference on Sustainable Energy and Environmental Sciences (SEES 2013), pp 28-33

10. Kundur P (1994) Power sys. stability and control. McGraw-Hill, USA

11. Powerforce APP Ltd. Technical, standards and control issues of embedded generation. DTI Pub. URN 00/1449

12. Anderson PM, Bose A (1983) Stability simulation of wind turbine systems. Trans Power App Syst PAS 102(12):3791-3795

13. Arrillaga J, Liu YH, Watson NR (2007) Flexible power transmission, the HVDC options. Wiley, UK

14. Suh Y, Tijeras V, Lipo TA. A nonlinear control of the instantaneous power in dq synchronous frame for PWM AC/DC converter under generalized unbalanced operating conditions, 37th IAS Annual Meeting. Conference Record of the Industry Applications Conference, 2002., vol.2, pp. 1189- 1196

15. Gole AM, Filizadeh S, Menzies RW, Wilson PL (2005) Optimization-enabled electromagnetic transient simulation. IEEE Trans Power Deliv 20:512-518

16. GE Power Management, Load shedding, load restoration and generator protection using solid-state and electromechanical under frequency relays, Ontario, Canada, Rep. GET-6449

17. Zin AAM, Hafcz HM, Wong WK (2004) Static and dynamic under-frequency load shedding: a comparison. In: Proceedings International Conference on Power System TechnologyPOWERCON 2004, vol 1, Singapore, pp 941-945

18. Transend Networks Pty Ltd, Frequency Standard Development, Final Report to Alinta Power, TrimD07/:66728, 2007 [online]. Available at: http://www.aemc.gov.au/Media/ docs/Alinta\%20Submission\%20-\%20revised\%2021\%20May \%202008-d0ad3b48-a016-470c-aa9dcb4e90206c55-0.pdf

19. Delfino B, Massucco S, Morini A, Scalera P, Silvestro F (2001) Implementation and comparison of different under frequency load-shedding schemes. In: Power Engineering Society Summer Meeting, vol 1. IEEE, pp 307-312

20. Lidula NWA, Rajapakse AD (2012) A pattern recognition approach for detecting power islands using transient signals?Part II: Performance Evaluation. IEEE Trans Power Deliv 27(3):10711080

21. EL-Fouly THM, Abbey C (2009) Commercial relays field tests for passive anti-islanding protection schemes of synchronous generator based DGs. In: CIGRÉ Canada Conference on Power Systems, Toronto. Paper \# 164

22. Funabashi T, Koyanagi K, Yokoyama R A review of islanding detection methods for distributed resources. In: Proceedings in Power Technological Conference 2003, vol 2. IEEE, Bologna, pp 6-11

23. Xu W, Mauch K, Martel S (2004) An Assessment of DG Islanding Detection Methods and Issues for Canada, report \# CETCVarennes 2004-074 (TR), CANMET Energy Technology Centre? Varennes, Natural Resources Canada

24. Etxegarai A, Eguía P, Zamora I (2011) Analysis of remote islanding detection methods for distributed resources. International Conference on Renewable Energies and Power Quality (ICREPQ'11)

25. Lidula NWA, Rajapakse AD (2010) A pattern recognition approach for detecting power islands using transient signalsPart I: design and implementation. IEEE Trans Power Deliv 25(4):3070-3077 